\title{
MHD Stagnation Point Flow and Heat Transfer over a Permeable Surface
}

\author{
Santosh Chaudhary, Pradeep Kumar \\ Department of Mathematics, Malaviya National Institute of Technology, Jaipur, Rajasthan, India \\ Email: d11.santosh@yahoo.com,pradeep17matrix@gmail.com
}

Received October 20, 2012; revised November 21, 2012; accepted December 8, 2012

\begin{abstract}
The steady two-dimensional, laminar flow of a viscous, incompressible, electrically conducting fluid near a stagnation point with heat transfer over a permeable surface in the presence of a uniform magnetic field is considered. Taking suitable similarity variables, the governing boundary layer equations are transformed to ordinary differential equations and solved numerically by Shooting method. The effects of the suction parameter, the magnetic parameter, the Prandtl number and the Eckert number are studied on the velocity and temperature distributions.
\end{abstract}

Keywords: MHD; Stagnation Point; Heat Transfer; Permeable Surface

\section{Introduction}

In recent years, the requirements of modern technology have stimulated interest in fluid flow studies which involve interaction of several phenomena. One such study is stagnation point flow over a permeable surface which plays an important role in many engineering problems, petroleum industries, ground water flows, extrusion of a polymer sheet from a dye and boundary layer control. More importantly, the quality of the products, in the above mentioned processes, depends on the kinematics of stretching and the simultaneous heat and mass transfer rates during the fabrication process. Crane [1] studied the flow over a linearly stretching sheet in an ambient fluid and gave a similarity solution in closed analytical form for the study of two-dimensional problem. Heat transfer in the flow over a permeable surface has been investigated by several authors such as Gupta and Gupta [2], Carragher and Crane [3], Chiam [4], Magyari and Keller [5], Mahapatra and Gupta [6], Elbashbeshy and Bazid [7], Liao and Pop [8], Jat and Chaudhary [9,10] and Bhattacharya and Layek [11].

The object of the present paper is to study the stagnation point flow and heat transfer for an electrically conducting fluid over a permeable surface in the presence of a magnetic field. The fluid is acted upon by an external uniform magnetic field and a uniform injection or suction directed normal to the plane of the wall. The wall and stream temperatures are assumed to be constants. Numerical results are obtained for the momentum and energy equations using Shooting method.

\section{Formulation of the Problem}

Consider the steady two-dimensional stagnation point flow $(u, v, 0)$ of a viscous incompressible electrically conducting fluid near a stagnation point over a permeable surface placed in the plane $y=0$ of a Cartesian coordinates system with the $x$-axis along the surface, in a uniform injection or suction velocity $\left( \pm v_{0}\right)$ at the boundary of the surface and in the presence of an externally applied normal magnetic field of constant strength $\left(0, H_{0}, 0\right)$. The stretching surface has a uniform temperature $T_{w}$ while the velocity of the flow external to the boundary layer is $u_{e}$ and temperature $T_{\infty}$. The system of boundary layer equations (which model Figure 1) are given by:

$$
\begin{aligned}
& \frac{\partial u}{\partial x}+\frac{\partial v}{\partial y}=0 \\
& u \frac{\partial u}{\partial x}+v \frac{\partial u}{\partial y} \\
& =u_{e} \frac{\mathrm{d} u_{e}}{\mathrm{~d} x}+v \frac{\partial^{2} u}{\partial y^{2}}-\frac{\sigma \mu_{e}^{2} H_{0}^{2} u}{\rho} \\
& \rho C_{p}\left(u \frac{\partial T}{\partial x}+v \frac{\partial T}{\partial y}\right) \\
& =\kappa \frac{\partial^{2} T}{\partial y^{2}}+\mu\left(\frac{\partial u}{\partial y}\right)^{2}+\sigma \mu_{e}^{2} H_{0}^{2} u^{2}
\end{aligned}
$$

where $v$ is the coefficient of kinematic viscosity, $\sigma$ the electrical conductivity, $\mu_{e}$ the magnetic permeability, $\rho$ the density, $C_{p}$ the specific heat at constant 


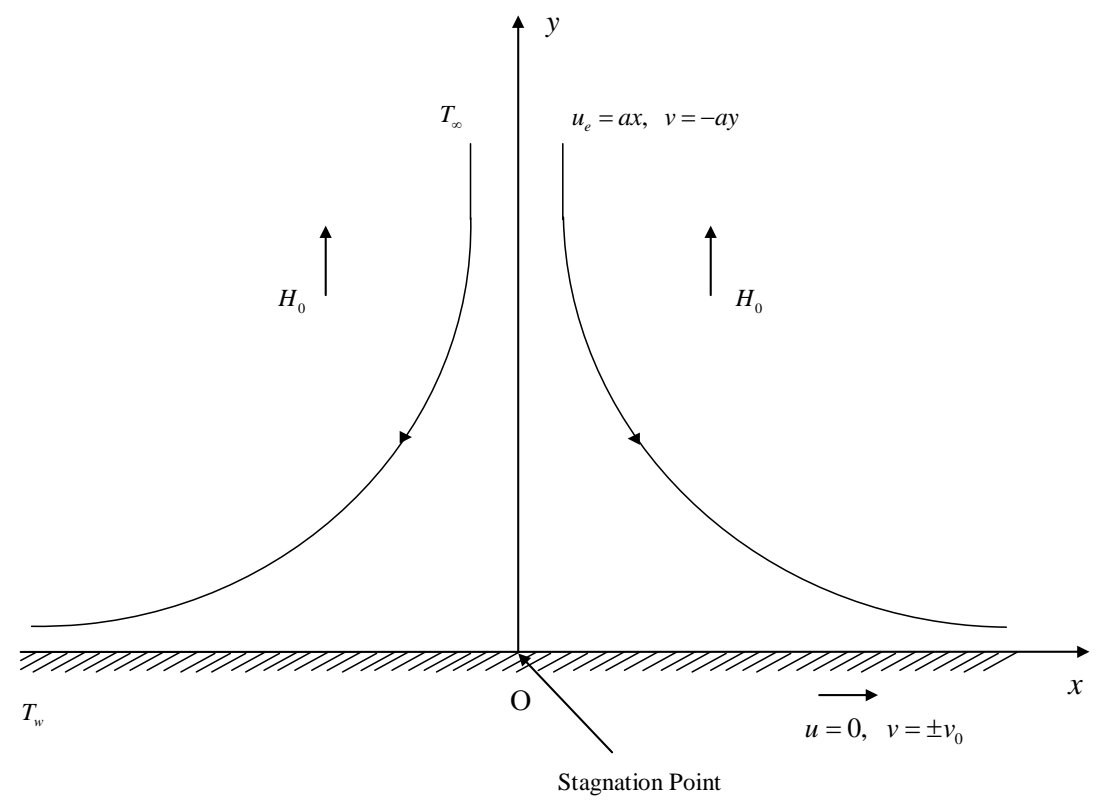

Figure 1. A sketch of the physical problem.

pressure, $\kappa$ the thermal conductivity and $\mu$ the coefficient of viscosity. The other symbols have their usual meanings.

The boundary conditions are:

$$
\begin{aligned}
& y=0: \quad u=0, v= \pm v_{0} ; T=T_{w} \\
& y=\infty: \quad u=u_{e}=a x, v=-a y ; T=T_{\infty}
\end{aligned}
$$

where $a$ is a constant proportional to the free stream velocity far away from the stretching surface.

\section{Analysis}

The continuity Equation (1) is identically satisfied by stream function $\psi(x, y)$, defined as

$$
u=\frac{\partial \psi}{\partial y}, \quad v=-\frac{\partial \psi}{\partial x}
$$

For the solution of the momentum and the energy Equations (2) and (3), the following dimensionless variables are defined:

$$
\begin{aligned}
& \psi(x, y)=\sqrt{a v} x f(\eta) \\
& \eta=\sqrt{\frac{a}{v}} y \\
& \theta(\eta)=\frac{T-T_{\infty}}{T_{w}-T_{\infty}}
\end{aligned}
$$

Equations (5) to (8), transform Equations (2) and (3) into

$$
\begin{array}{r}
f^{\prime \prime \prime}+f f^{\prime \prime}-f^{\prime 2}-\operatorname{Re}_{m}^{2} f^{\prime}+1=0 \\
\theta^{\prime \prime}+\operatorname{Pr} f \theta^{\prime}+\operatorname{Pr} E c f^{\prime \prime 2}+\operatorname{Pr} E c \operatorname{Re}_{m}^{2} f^{\prime 2}=0
\end{array}
$$

where a prime (') denotes differentiation with respect to $\eta, \operatorname{Re}_{m}=\mu_{e} H_{0} \sqrt{\frac{\sigma}{\rho a}}$ the Magnetic parameter, $\operatorname{Pr}=\frac{\mu C_{p}}{\kappa}$ the Prandtl number and $E c=\frac{u_{e}^{2}}{C_{p}\left(T_{w}-T_{\infty}\right)}$ the Eckert number.

The corresponding boundary conditions are:

$$
\begin{aligned}
& \eta=0: \quad f=A, f^{\prime}=0 ; \quad \theta=1 \\
& \eta=\infty: \quad f^{\prime}=1 ; \theta=0
\end{aligned}
$$

where $A= \pm \frac{v_{0}}{\sqrt{a v}}$ is the suction parameter.

For numerical solution of the Equations (9) and (10), we apply the following power series in a small magnetic parameter $\operatorname{Re}_{m}^{2}$ as:

$$
\begin{aligned}
& f(\eta)=\sum_{i=0}^{\infty}\left(\operatorname{Re}_{m}^{2}\right)^{i} f_{i}(\eta) \\
& \theta(\eta)=\sum_{j=0}^{\infty}\left(\operatorname{Re}_{m}^{2}\right)^{j} \theta_{j}(\eta)
\end{aligned}
$$

Substituting Equations (12) and (13) and its derivatives in Equations (9) and (10) and then equating the coefficients of like powers of $\mathrm{Re}_{m}^{2}$, we get the following set of equations:

$$
\begin{gathered}
f_{0}^{\prime \prime \prime}+f_{0} f_{0}^{\prime \prime}-f_{0}^{\prime 2}+1=0 \\
\theta_{0}^{\prime \prime}+\operatorname{Pr} f_{0} \theta_{0}^{\prime}=-\operatorname{Pr} E c f_{0}^{\prime 2} \\
f_{1}^{\prime \prime \prime}+f_{0} f_{1}^{\prime \prime}-2 f_{0}^{\prime} f_{1}^{\prime}+f_{0}^{\prime \prime} f_{1}=f_{0}^{\prime} \\
\theta_{1}^{\prime \prime}+\operatorname{Pr} f_{0} \theta_{1}^{\prime}=-\operatorname{Pr} f_{1} \theta_{0}^{\prime}-\operatorname{Pr} E c\left(2 f_{0}^{\prime \prime} f_{1}^{\prime \prime}+f_{0}^{\prime 2}\right)
\end{gathered}
$$




$$
\begin{aligned}
f_{2}^{\prime \prime \prime}+f_{0} f_{2}^{\prime \prime}-2 f_{0}^{\prime} f_{2}^{\prime}+f_{0}^{\prime \prime} f_{2}=-f_{1} f_{1}^{\prime \prime}+\left(f_{1}^{\prime}+1\right) f_{1}^{\prime} \\
\theta_{2}^{\prime \prime}+\operatorname{Pr} f_{0} \theta_{2}^{\prime}=-\operatorname{Pr}\left(f_{1} \theta_{1}^{\prime}+f_{2} \theta_{0}^{\prime}\right) \\
-\operatorname{Pr} E c\left(2 f_{0}^{\prime \prime} f_{2}^{\prime \prime}+f_{1}^{\prime \prime 2}+2 f_{0}^{\prime} f_{1}^{\prime}\right)
\end{aligned}
$$

(18) hary [9] for the non-magnetic case and the remaining equations are ordinary linear differential equations and have been solved numerically by Shooting method. The velocity and temperature distributions for various values of parameters are shown in Figures 2-4 respectively.

with the boundary conditions:

$$
\begin{aligned}
& \eta=0: f_{0}=A, f_{i}=0, f_{j}^{\prime}=0 ; \theta_{0}=1, \theta_{i}=0 \\
& \eta=\infty: f_{0}^{\prime}=1, f_{i}^{\prime}=0 ; \theta_{j}=0 \\
& i>0, j \geq 0
\end{aligned}
$$

The Equation (14) is that obtained by Jat and Chaud-

\section{Results and Discussion}

The Figure 2 shows the variation of velocity distribution against $\eta$ for various values of the suction parameter $A$ and the magnetic parameter $\mathrm{Re}_{m}$. It may be observed that the velocity increases as the suction parameter $A$

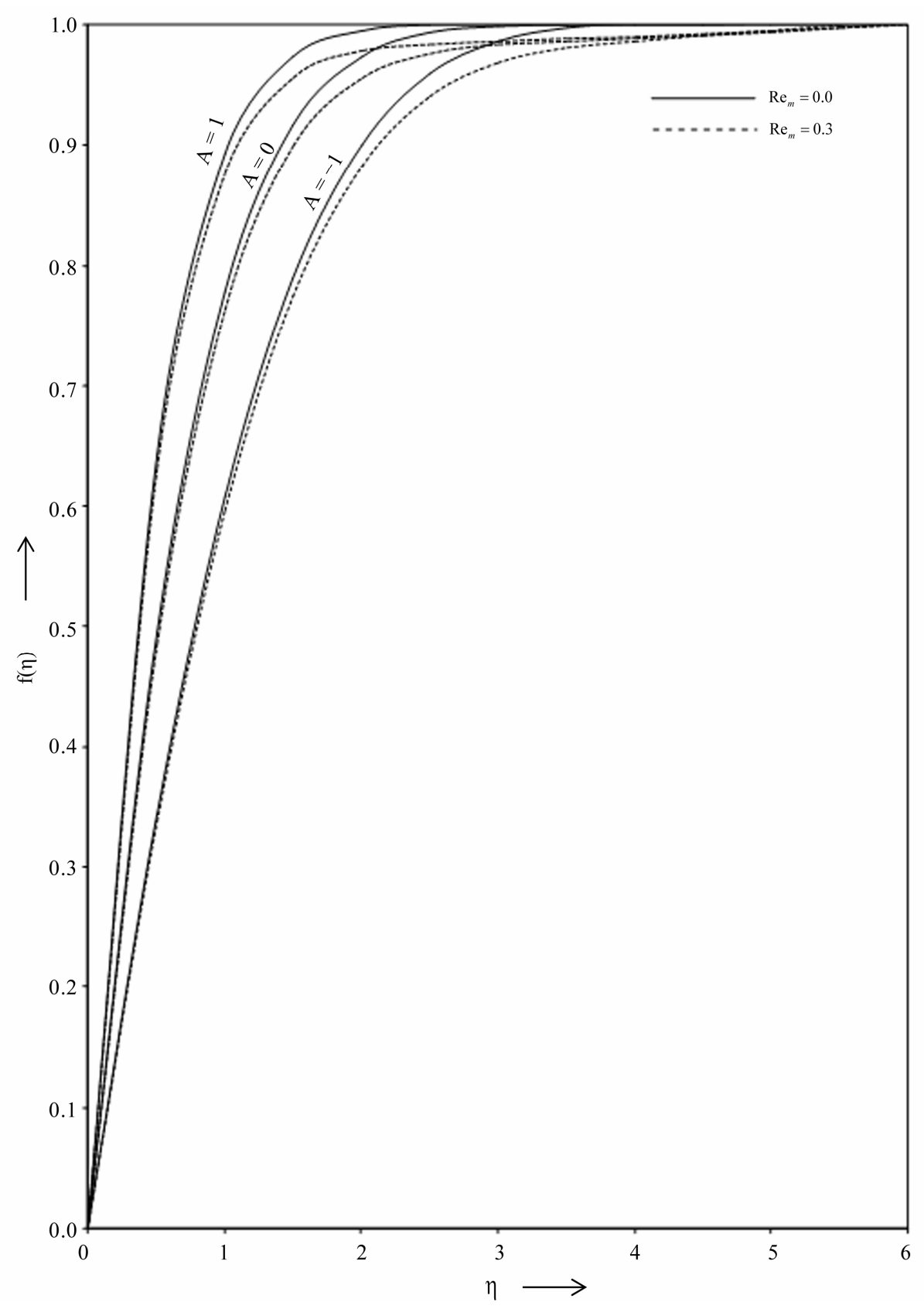

Figure 2. Velocity distribution against $\boldsymbol{\eta}$ for various values of $A$ and $\operatorname{Re}_{m}$. 


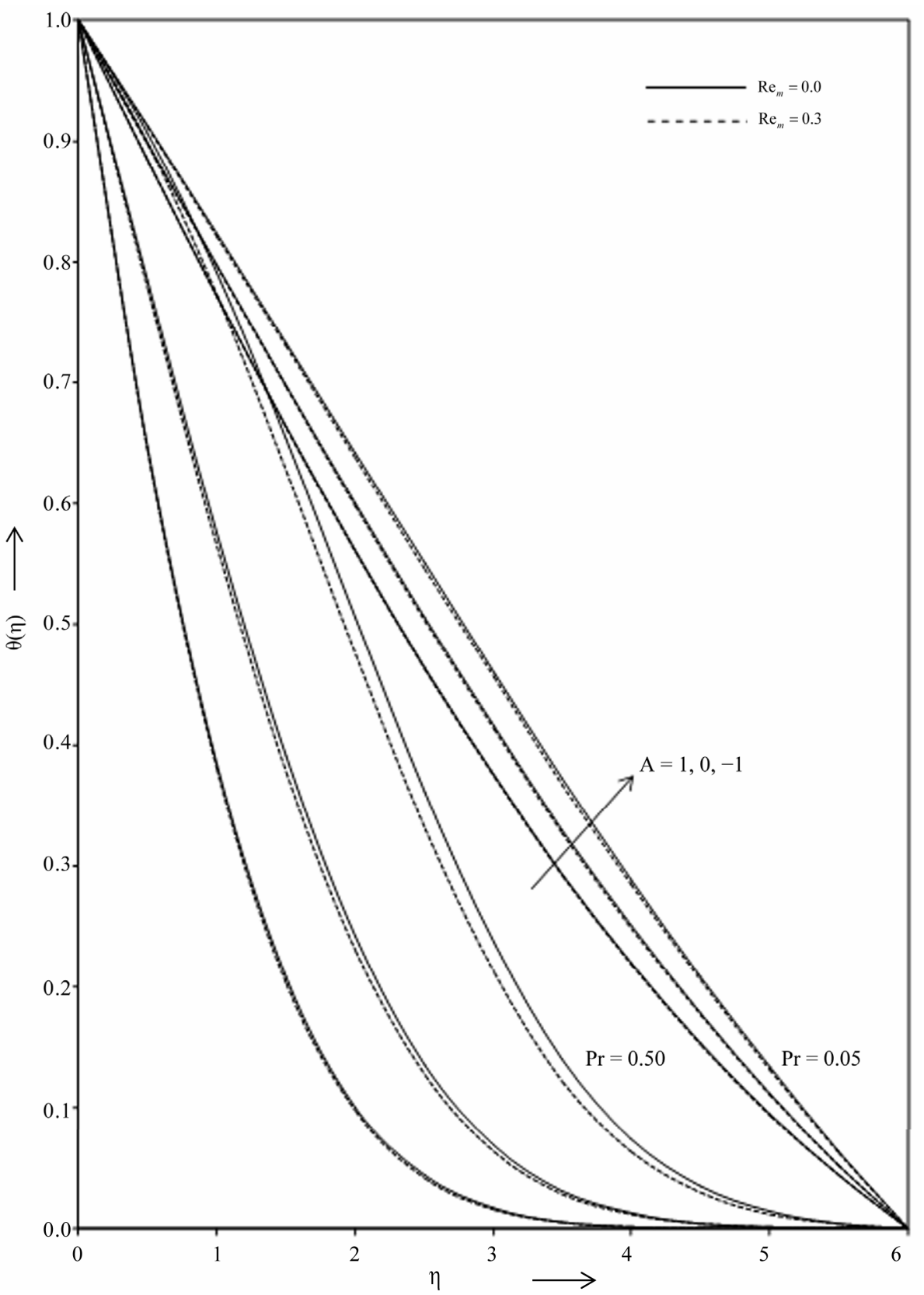

Figure 3. Temperature distribution against $\eta$ for various values of $A, \operatorname{Re}_{m}$ and $\operatorname{Pr}$ with $E c=0.00$.

increases, whereas it decreases as the magnetic parameter $\mathrm{Re}_{m}$ increases for a fixed $\eta$.

The Figures 3 and $\mathbf{4}$ show the variation of the temperature distribution against $\eta$ for various values of the parameters such as the suction parameter $A$, the magnetic parameter $\mathrm{Re}_{m}$, the Prandtl number $\operatorname{Pr}$ and the Eckert number $E c$. From these figures it may be observed that the temperature distribution decreases with the increasing value of the suction parameter $A$ and same phenomena occur for the Prandtl number Pr. It is further observed that in Figure 3 the temperature distribution decreases with the increasing value of the magnetic parameter
$\mathrm{Re}_{m}$. In Figure 4, for fixed suction parameter $A$ temperature distribution decreases with the increasing value of the Eckert number $E c$ and reverse phenomena occurs for the magnetic parameter $\mathrm{Re}_{m}$.

\section{Conclusions}

The steady two-dimensional stagnation point flow and heat transfer of a viscous incompressible electrically conducting fluid over a permeable surface has been analyzed. The similarity equations are obtained and solved numerically by a Shooting method. The effects of the 


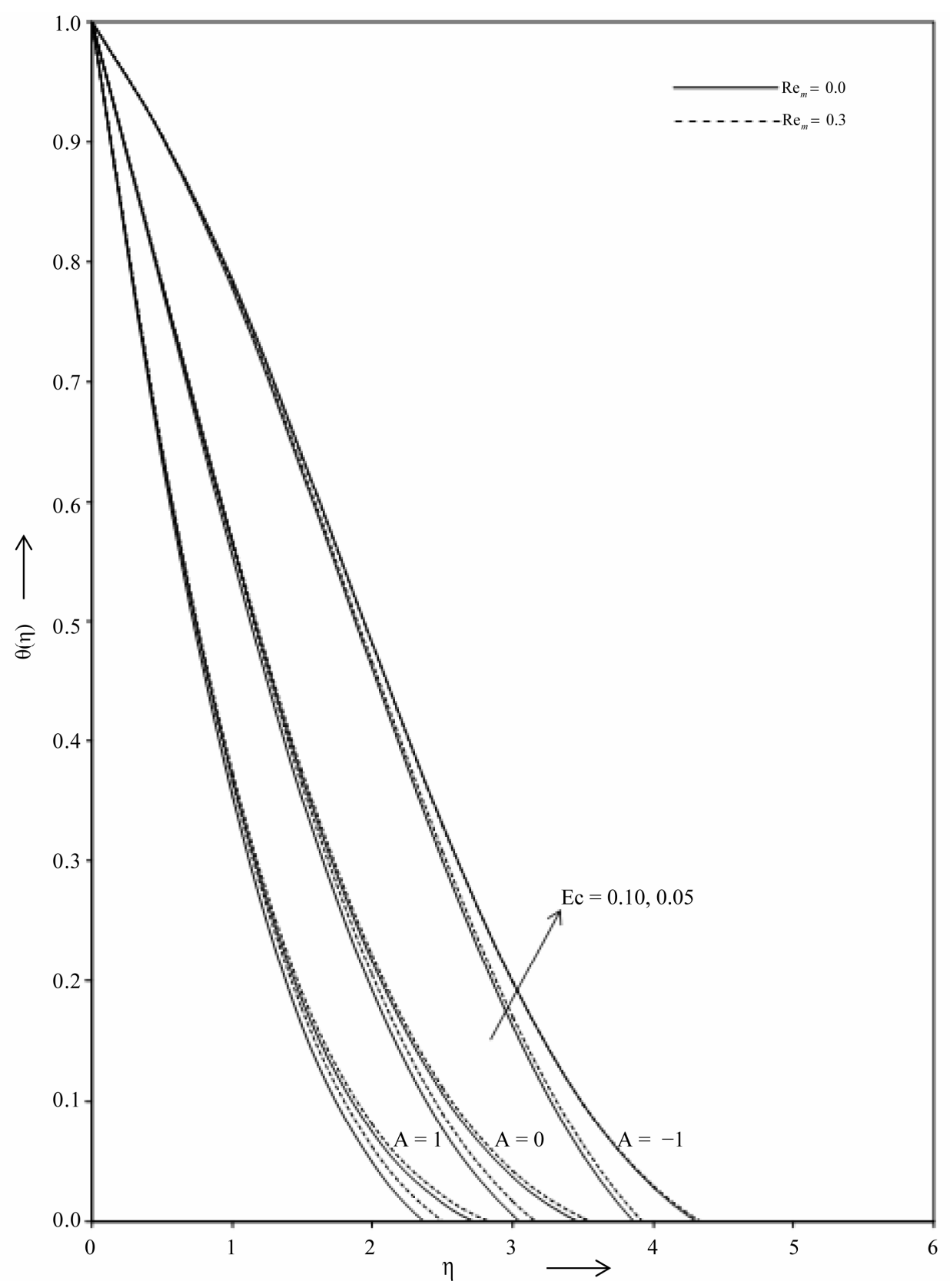

Figure 4. Temperature distribution against against $\eta$ for various values of $A, \operatorname{Re}_{m}$ and $E c$ with $\operatorname{Pr}=0.50$.

suction parameter, the magnetic parameter, the Prandtl number and the Eckert number are studied in detail. The velocity boundary layer thickness increases with the increasing value of the suction parameter while the reverse phenomenon is observed for thermal boundary layer thickness. Further concluded when the Eckert number equal to zero the velocity as well as thermal boundary layer thickness decreases with the increasing value of the magnetic parameter and the Prandtl number, whereas for the Eckert number not equal to zero, thermal boundary layer thickness increases with the increasing value of the magnetic parameter and decreases with the increasing value of the Eckert number.

\section{REFERENCES}

[1] L. J. Crane, "Flow Past a Stretching Plate,” Zeitschrift für Angewandte Mathematik und Physik, Vol. 21, No. 4, 1970, pp. 645-647. doi:10.1007/BF01587695

[2] P. S. Gupta and A. S. Gupta, "Heat and Mass Transfer on a Stretching Sheet with Suction or Blowing," Canadian Journal of Chemical Engineering, Vol. 55, No. 6, 1977, pp. 744-746. doi:10.1002/cjce.5450550619

[3] P. Carragher and L. J. Crane, "Heat Transfer on a Continuous Stretching Sheet," Zeitschrift für Angewandte Mathematik und Mechanik, Vol. 62, No. 10, 1982, pp. 
564-573. doi:10.1002/zamm.19820621009

[4] T. C. Chiam, "Stagnation-Point Flow towards a Stretching Plate,” Journal of the Physical Society of Japan, Vol. 63, 1994, pp. 2443-2444. doi:10.1143/JPSJ.63.2443

[5] E. Magyari and B. Keller, "Exact Solutions for Self Similar Boundary-Layer Flows Induced by Permeable Stretching Surfaces,” European Journal of MechanicsB/Fluids, Vol. 19, No. 1, 2000, pp. 109-122. doi:10.1016/S0997-7546(00)00104-7

[6] T. R. Mahapatra and A. S. Gupta, "Heat Transfer in Stagnation-Point Flow towards a Stretching Sheet," Heat and Mass Transfer, Vol. 38, No. 6, 2002, pp. 517-521. doi:10.1007/s002310100215

[7] E. M. A. Elbashbeshy and M. A. A. Bazid, "Heat Transfer over an Unsteady Stretching Surface with Internal Heat Generation," Applied Mathematics and Computation, Vol. 138, No. 2-3, 2003, pp. 239-245. doi:10.1016/S0096-3003(02)00106-6
[8] S. J. Liao and I. Pop, "On Explicit Analytic Solutions of Boundary Layer Equations about Flow in Porous Medium or for a Stretching Wall," International Journal of Heat and Mass Transfer, Vol. 47, No. 1, 2004, pp. 75-85. doi:10.1016/S0017-9310(03)00405-8

[9] R. N. Jat and S. Chaudhary, "MHD Stagnation Flows with Slip,” Il Nuovo Cimento, Vol. 122B, No. 8, 2007, pp. 823-831.

[10] R. N. Jat and S. Chaudhary, "Magnetohydrodynamic Boundary Layer Flow near the Stagnation Point of a Stretching Sheet," Il Nuovo Cimento, Vol. 123B, No. 5, 2008, pp. 555-566.

[11] K. Bhattacharyya and G. C. Layek, "Effects of Suction/ Blowing on Steady Boundary Layer Stagnation-Point Flow and Heat Transfer towards a Shrinking Sheet with Thermal Radiation,” International Journal of Heat and Mass Transfer, Vol. 54, No. 1-3, 2011, pp. 302-307. doi:10.1016/j.ijheatmasstransfer.2010.09.043 